\title{
The Adsorption Mechanism of Activated Carbon and Its Application - A Review
}

\author{
Muhammad S. Muzarpar*a, A. M. Lemanª, K.A Rahman ${ }^{\text {b }}$ Norhafsam Maghporc, Nik \\ Normunirah Mat Hassanª, Norasyikin Misdana \\ ${ }^{a}$ Faculty of Engineering Technolgy, Universiti Tun Hussein Onn Malaysia, Hab Pendidikan Tinggi Pagoh, Muar, \\ Johor, Malaysia \\ ${ }^{b}$ Department of Petrochemical Engineering, Politeknik Tun Syed Nasir, Pagoh Higher Education Hub, Muar, \\ Johor, Malaysia \\ ${ }^{c}$ National Institute of Occupational Safety and Health, Bandar Baru Bangi, Selangor, Malaysia
}

\begin{abstract}
Activated carbon (AC) was recognized by many researchers as useful substance in adsorption of impurities. Several processes involved in the production of AC which were carbonization, crushing, and activation process. Carbonization of carbon required high temperature up to $900^{\circ} \mathrm{C}$. Then the carbon will be crush to a desired size for activation process. Activation of carbon can be either chemical activation, physical activation or combination of chemical and physical activation which called physiochemical activation. The mechanism adsorption of AC commonly due to its micropore present in the carbon or the weak vander waals forces which can attract the impurities. Activated carbon have multiple function in human daily life. This study will be discussing the function of $\mathrm{AC}$ in the production face mask, water filtration and air filtration.
\end{abstract}

Keywords: activated carbon; carbonization; vander waals forces; face mask; water filtration; air filtration

DOI: $10.37869 /$ ijatec.v1i3.37

Received 14 December 2020; Accepted 1 January 2021; Available online 1 January 2021

(C) The Authors. Published by IRIS. This is an open access article under the CC BY-NC-SA license cc) (i) (3) (2)

\section{Introduction}

Its was known to world that the usage and application of activated carbon as multipurpose adsorbent. Some using activated carbon as air purification and other used as waster waste treatment. The previous works explained and supported the usage of activated carbon which mentioned that Activated carbon can be call as "material of the future" due to its versatility usage from medical aspect, water and air treatment and a very good adsorbent characteristic [1]. The used of carbon in daily life were back dated in early civilization. [2,3] mentioned that The origin of activated carbon (AC) is associated with Ancient Egypt (1500 BC), whereby the Egyptians make use of its adsorbent characteristics for water purifications and medicinal purposes also highlight that, in olden days (1500 B.C) activated charcoal has been used for medicinal application Before the carbon can be produce and used, the selection of material, process and end product must be identified for a better knowledge regarding the adsorption mechanism of an activated carbon. 


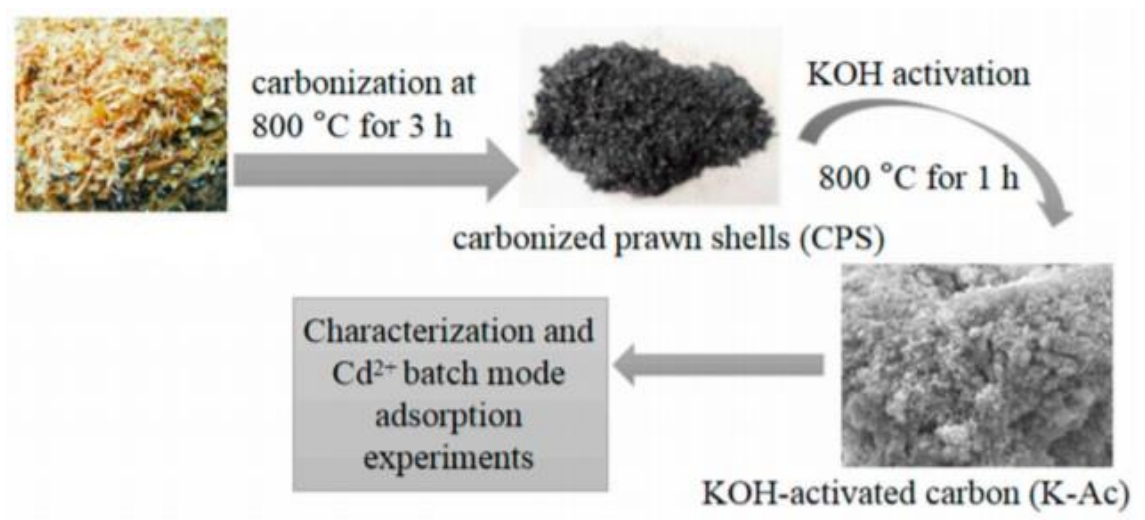

Figure 1. Flow process of AC production [4]

\section{Mechanism of Adsorption}

The process by which a solid surface concentrates fluid molecule by physical forces is known as adsorption (whereas absorption is a process whereby fluid molecules are taken up by a liquid and distributed throughout that liquid). The adsorption of AC influence by several factor, in this research the adsorption mechanism of AC will be focus on its microspore and weak van der waals forces.

\subsection{Microspore structure}

Microspore formation in AC formed during the burning process of AC. According to [5], Activated carbons (ACs) are well-known conventional adsorbents with many applications due to their hydrophobicity, surface functionality, pore structure, and high surface area. The raw materials that undergoes burning process will be converted to charcoal. In this process the particle structure of the raw material will be restructure. Activated carbon (AC)was prepared from date palm leaflets using $\mathrm{KOH}$ activation followed by nitric acid oxidation to produce oxidized activated carbon (OAC) which possesses acidic and increase in pore number [6]. The bond between each particle will be break and change into new bond which will create the porous of the material. However, the present spore does not effective as the activated carbon since the number of microspores is less. [7] highlighted from study which mentioned that the sorbent is mainly microporous (with a micropore volume equal to $0.31 \mathrm{~cm} 3 \mathrm{~g}-1$ ) Hence in order to increase the effectiveness the charcoal must be further process which was the activation process. Throughout activation process more and more of the microspore will be formed alternatively increase the surface area of AC. Microspore were very small and only be seen under SEM. Relatively the microspore act similar to sponge. Sponge which has numerus hole in it can traps dust and other substance. The function of microspore in AC can be related to sponge as its allowed substance to be traps inside it in much smaller size.

\subsection{Weak van der waals forces}

The elemental force causing physical adsorption on activated carbon is the London dispersion force, a form of Van der Waals force, resulting from intermolecular attraction. In the case of adsorption, carbon and the adsorbate are thus chemically unchanged. However, in the process known as chemisorption, molecules chemically react with the carbon's surface (or an impregnant on the carbon's surface) and are held by chemical bonds that are much stronger forces compared to London dispersion forces. The London dispersion force is an intermolecular interaction that exists between all molecules (both polar and non-polar), but it is extremely short-ranged. [8] state that the rich AC has a characteristic that may be favorable for the adsorption of cationic species such as dyes through electrostatic interaction. MB is chosen a typical cationic dye to investigate the adsorption capacity. It is responsible for condensation of most gases to liquids, and the reason higher-molecular-weight gases have higher boiling points. The observed London force is the sum of all the individual interactions of the adsorbate molecule and the neighboring graphite plates composing the carbon structure. The magnitude of the adsorption force will be related to the number of carbon plates, or density of carbon, within the vicinity of the adsorbate molecules. London forces exist between all molecules. Therefore, all molecules adsorb on activated carbon to some extent, depending on their vapor pressure and solubility at the carbon temperature. The London forces are unaffected by 
temperature, and thus the adsorption force field will be constant with temperature. The carbon adsorption capacities will still be sensitive, however, to the changes with temperature in vapour pressure or solubility of the adsorbing molecules. The magnitude of the London force is very sensitive to the separation of the adsorbate molecule from the graphite plate. The London force can be considered negligible with a separation greater than about two molecular layers. Therefore, the adsorption forces will only be significant if the gaps or voids within the carbon structure (pore widths) are less than four or five molecular layers. The first three characteristics of London forces are shared by another familiar force: gravity. London forces, and consequently the carbon adsorption forces, are analogous to gravitational forces. However, London forces are much shorter-ranged, and operate on a molecular scale instead of an astronomical scale [9]. [10] support the statement by mentioned that adsorption is the process by which fluid molecules become attached to a surface by physical or chemical forces or combination of both forces. In physical adsorption the impurities are held on the surface of carbon by low level van der Waals forces while in chemisorption the force are relatively strong and occur at active site on the surface.

\section{Application of Activated Carbon}

Wide range in application of AC drive researcher from all around the world to study more on this useful material. For the purposed of this study, the usage of AC in face mask, air filter and water treatment will be further discussed.

\subsection{Face mask}

Granular activated carbon (GAC) has been the most common adsorbent used in respirators for protection against gas phase contaminants [11]. Activated carbon fiber (ACF) is considered as an alternative adsorbent to GAC since it has been shown to be effective in capturing volatile organic compounds (VOCs) from gas streams at wide range of concentrations [12,13]. The small fiber diameter ofACF (ranging from10-20 um) allows homogeneous activation of the fibers, resulting to a unimodal, narrow pore size distribution in the micropore range. ACFs have been assessed for air pollution control of VOCs Other ACF applications include energy saving and storage, CO2 capture, and SO2 removal [14]. Respirator or face mask were important especially in workplace to prevent dust and any substance from entering the lung which can cause sickness.

Table 1. substance present in workplace [15]

\begin{tabular}{|c|c|c|c|}
\hline No. & Form & Properties & Sample of substance \\
\hline 1. & Solid particle & $\begin{array}{l}\text { Particle in solid material, } \\
\text { including aerosol, dust, smoke, } \\
\text { fibre and fume }\end{array}$ & $\begin{array}{l}\text { Smoke, welding fume, wood dust, engine } \\
\text { exhaust, asbestos dust and flour }\end{array}$ \\
\hline 2. & $\begin{array}{l}\text { Liquid } \\
\text { particle }\end{array}$ & $\begin{array}{l}\text { Mist, fine spray and aerosol that } \\
\text { made a small droplet of liquid }\end{array}$ & $\begin{array}{l}\text { Pesticide, paints, Liquid jetting and powder } \\
\text { coating mix }\end{array}$ \\
\hline 3. & Vapour & $\begin{array}{l}\text { Gaseous forms from solid and } \\
\text { liquid }\end{array}$ & Mercury and solvent vapour \\
\hline 4 , & Gas & Gaseous & $\begin{array}{l}\text { Engine exhaust gases, carbon monoxide, } \\
\text { chlorine and sewer gas. }\end{array}$ \\
\hline
\end{tabular}

Wearing a respiratory mask is considered to be one of the most affordable and effective methods to reduce exposure to airborne pollutants. For various commercially available respirators, N95 FFRs, surgical mask and activated carbon mask are widely studied [16]. [17] discover that carbon impregnated in fibre cause substrate to attached to elementary fibres but not embedded in their structure, which is important because the deposition of carbon adsorbent in the nonwoven structure can significantly impact the sorption properties of the material. The activated carbon combination mask model group has a higher ability than other mask models in absorbing VOCs [18].

\subsection{Air filter}

[19] mentioned that Activate carbon can clean the environment by absorbing the harmful gasses (COx, NOx, and SOx) from the air. These pollutant gases cause respiratory diseases, lung infection, 
breathing problems, cough, heart disease, and paralysis [20]. The removal efficiency depends on the characteristics of the feedstock (petroleum coke, coal, biomass), activators (potassium hydroxide, carbon dioxide, and phosphoric acid), and process variables (activation temperature, the ratio of activator to feedstock) [21]. AC filter demand increase vigorously in recent year recent years as a promising alternative adsorbent. They are prepared from fabric precursors and have a very high surface area and are used in the form of cloth or felt, making them much easier to handle than GAC therefore, they should be adaptable to many air cleanings purposes [22]. [23] has develop an integrated carbon fiber brush charger combined with a metallic collection rod and an activated carbon fiber (ACF) sheet that called electrostatic precipitation (ESP).

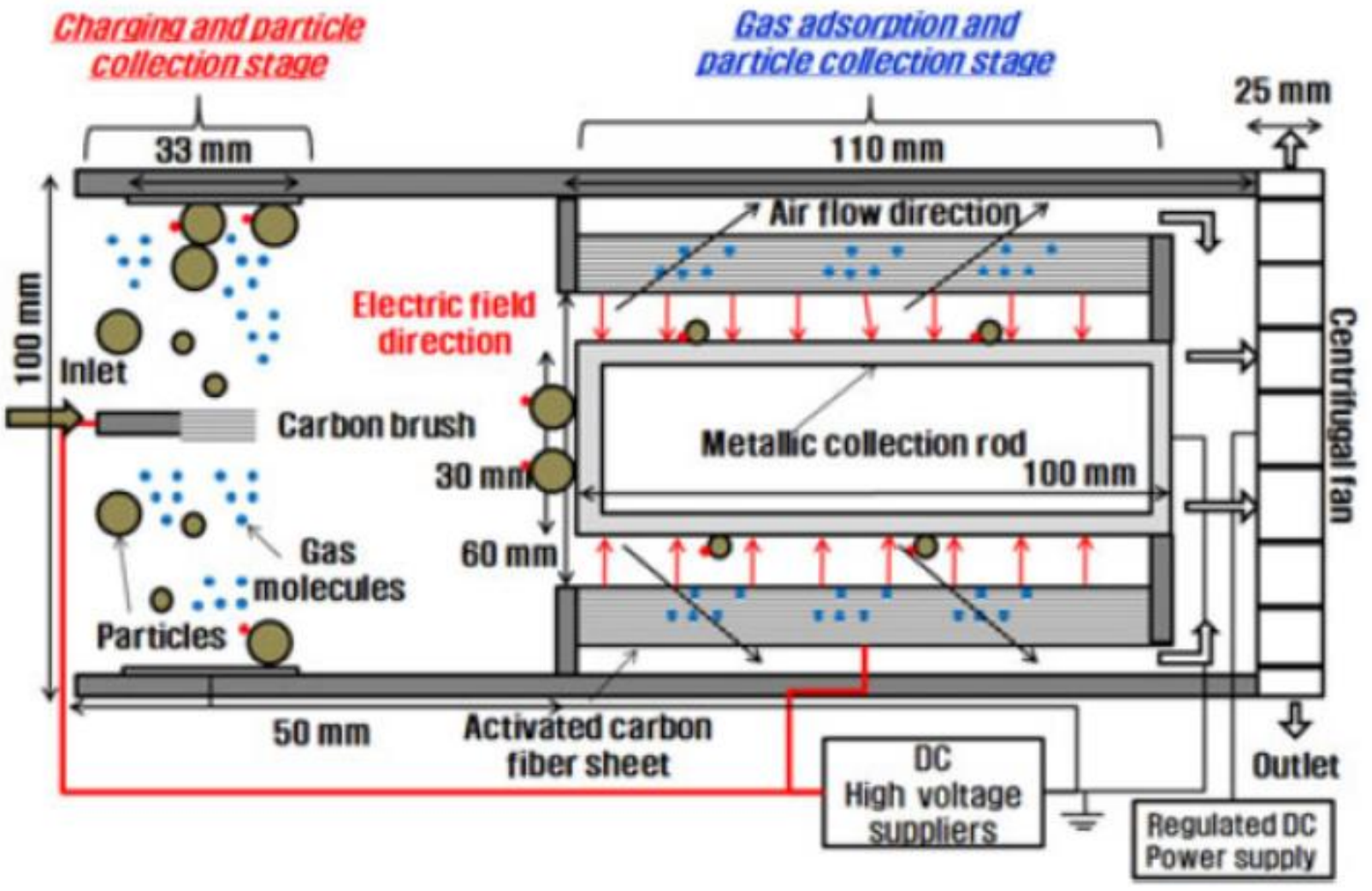

Figure 2. Schematic of the electrostatic precipitation (ESP) type air cleaner [23]

Granular activated carbon (GAC) filters have been widely used to remove harmful gaseous pollutants however, GACs have many weaknesses, including large pressure drops caused by packed media and continuous depletion of granular material. ACF filters are therefore beginning to receive attention as an alternative gaseous pollutant adsorbent [24] and as a gas adsorbent in novel small air purifiers. An excessive exposure to indoor toxic pollutant gases such as trimethylamine (TMA) and $\mathrm{H} 2 \mathrm{~S}$ is fatal to humans especially in the confined workspace. A porous carbon pollutant filter was developed using rice husk as a biomass waste. The different carbonization temperature highly affected on the surface area of ARH (activated rice husk carbon) and their performance of pollutant gas adsorption [25].

\subsection{Water treatment}

Adsorption onto granular activated carbon (GAC) is an established technology in water and advanced wastewater treatment for the removal of organic substances from the liquid phase. Besides adsorption, the removal of particulate matter by filtration and biodegradation of organic substances in GAC contactors has frequently been reported. The application of GAC as both adsorbent for organic micropollutant (OMP) removal and filter medium for solids retention in tertiary wastewater filtration represents an energy- and space saving option, but has rarely been considered because high dissolved organic carbon (DOC) and suspended solids concentrations in the influent of the GAC absorber put a significant burden on this integrated treatment step and might result in frequent 
backwashing and unsatisfactory filtration efficiency [26].[27] mentioned that, Among the modifications and methods proposed to improve the performance of water treatment process, the BAC treatment is one of the most promising, environmentally friendly and economically feasible processes. The BAC can overcome several limitations of AC treatment and other conventional water treatment processes. In recent years, there has been growing concern worldwide regarding nitrate (NO3-) contamination in groundwater and associated health problems. Most of conducted research have shown that the presence of large nitrate concentrations in potable water resources can potentially lead to the serious troubles, including eutrophication phenomenon and infectious diseases, such as cyanosis and cancer of the alimentary canal [28] and blue-baby syndrome among infants [29]. The World Health Organization (WHO) and US EPA have established the maximum contaminant level (MCL) of $10 \mathrm{mg} / \mathrm{L}$ for NO3-N in drinking water. Therefore, the removal of large nitrate concentrations from solution before their discharge into the drinking water resources is so crucial. To date, lots of environmental remediation techniques such as ion exchange, electrodialysis, reverse osmosis, catalytic denitrification and biological denitrification, chemical reductions using zero-valent iron (ZVI), and adsorption [30,31] were developed to remove nitrate from water. Research towards more cost effective without using any chemical in wastewater treatment proved that AC acts as very good adsorbent in filtering the water [32]. ACs are proven to be effective in removal of various pollutants from aqueous solutions, including dyes, pharmaceutical and personal care products (PPCPs), heavy metals, organic pollutants. Thus, the latest research papers on applications of ACs derived from biowaste are grouped into different categories according to the types of adsorbates studied. Each subsection contains a table that summarizes the important aspects of the latest research works, including type of biowaste used, preparation steps of the AC, together with removal efficiency or percentage removal of target pollutant [33]. According to [34], The last treatment of a drinking water treatment plant (DWTP) before water distribution is usually the disinfection process, in which a widely used oxidant is chlorine dioxide (ClO2). Activated carbon filters are used for dichlorination and adsorption. Dichlorination is a very rapid process, in which the activated carbon participates in the reaction and the free chlorine is converted to chloride.

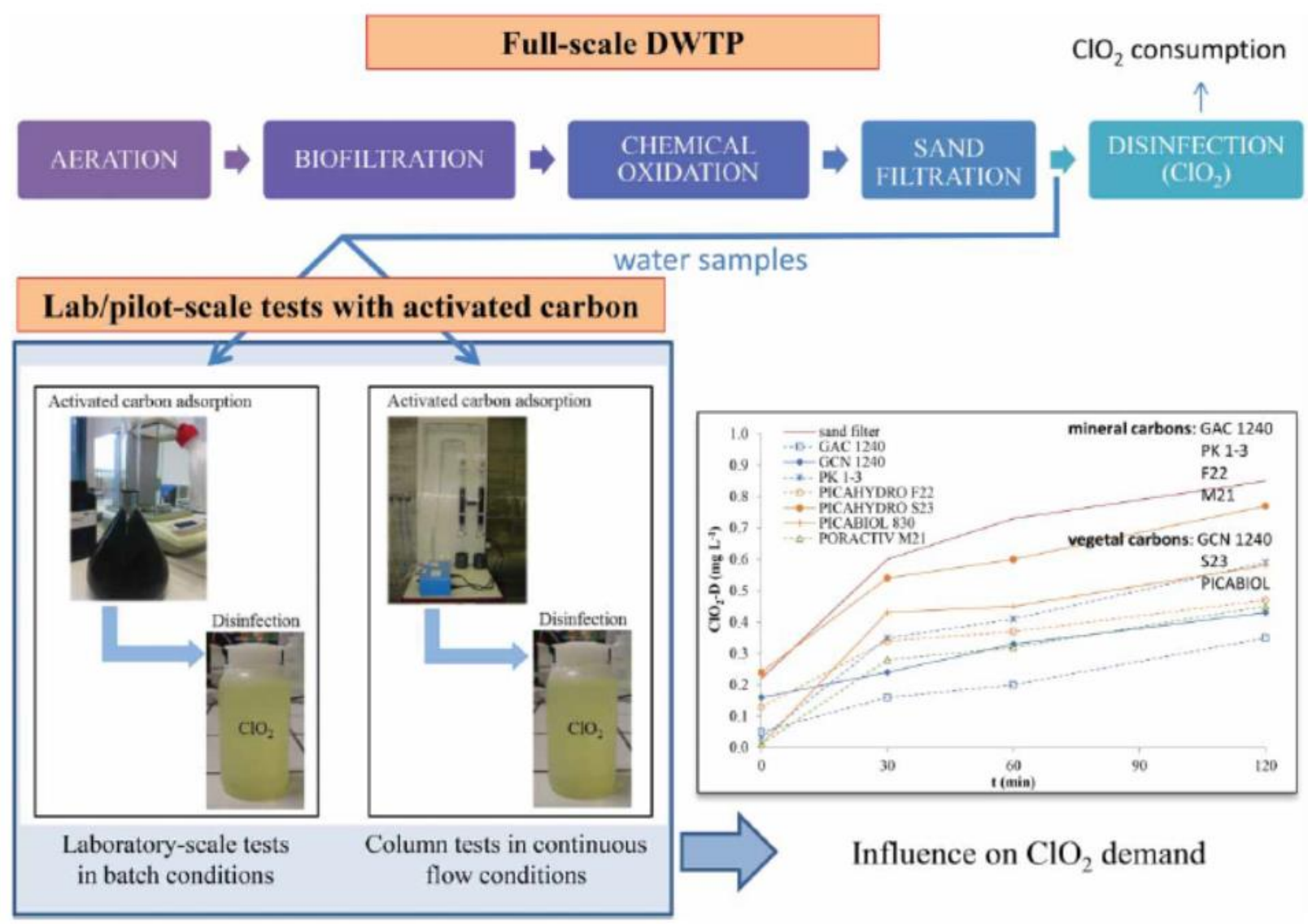

Figure 3. Pilot testing for chlorine oxide remover [34] 


\section{Conclusion}

This study is helpful in enhancing the knowledge regarding the adsorption mechanism of AC. AC were used since the beginning of human civilization as water filtration and medicine. Research on AC in term of perfecting the AC production was done by many researchers according to desire output. Based on this study:

- The materials selection, process involved, and end product of AC can be determined.

- The adsorption of AC which focusing on microspore and van der waals forces can be further studied.

- The application of AC as face mask, air filter and water treatment can be compared thoroughly in the present market demand.

\section{Acknowledgment}

The authors acknowledge Faculty of Engineering Technology, Universiti Tun Hussein Onn Malaysia for the lab and facilities provided throughout these studies. Also great thanks to all that contribute to this study directly or indirectly.

\section{References}

[1] M S Muzarpar, A M Leman, K A Rahman, Z Shayfull and A R Irfan. Exploration Sustainable Base Material for Activated Carbon Production Using Agriculture Waste as Raw Materials: A Review. Materials Science and Engineering 864 (2020).

[2] M A Tadda, A. Ahsan, A Shitu, M. ElSergany, T Arunkumar, J Bipin, M A Razzaque, N N Nik Daud. A review on activated carbon: process, application and prospects Journal of Advanced Civil Engineering Practice and Research 2(1). (2016).

[3] B Sadashiv and M Shivashankar. History, Method of Production, Structure and Applications of Activated Carbon Journal of Engineering Research \& Technology (IJERT) 6 495-498. (2017).

[4] Jian Guo, Yaqin Song, Xiaoyang Ji, Lili Ji, Lu Cai, Yaning Wang, Hailong Zhang and Wendong Song. Preparation and Characterization of Nanoporous Activated Carbon Derived from Prawn Shell and Its Application for Removal of Heavy Metal Ions. Materials (2019).

[5] Biswa Nath Bhadra, Pill Won Seo, and Sung Hwa Jhung. Adsorption of diclofenac sodium from water using oxidized activated carbon. Chemical Engineering Journal. (2016).

[6] El-Said I. El-Shafey Syeda N.F. Ali Saleh Al-Busafi Haider A.J. and Al-Lawati. Preparation and characterization of surface functionalized activated carbons from date palm leaflets and application for methylene blue removal. Journal of Environmental Chemical Engineering. (2016).

[7] P. Iovino, S. Canzano, S. Capasso, A. Erto, and D. Musmarra. A modeling analysis for the assessment of ibuprofen adsorption mechanism onto activated carbons. Chemical Engineering Journal 277. (2015)

[8] Zhigang Jia, Ziyu Li, Shengbiao Li, Yanhua Li, and Rongsun Zhu. Adsorption performance and mechanism of methylene blue on chemically activated carbon spheres derived from hydrothermally-prepared poly(vinyl alcohol) microspheres. Journal of Molecular Liquids 220 (2016).

[9] Basic of activated carbon adsorption retrieved from https://www.desotec.com/en/carbonology/carbonology-academy/what-adsorption on 29th august 2020

[10] Elwood v. Rinehart. Activated Carbon Basic. (2000).

[11] Jo Anne G. Balanay and Claudiu T. Lungu. Determination of pressure drop across activated carbon fiber respirator cartridges. Journal of Occupational and Environmental Hygiene. (2015).

[12] Tanada, S., N. Kawasaki, T. Nakamura, M. Araki, and Y. Tachibana: Characteristics of nonafluorobutyl methyl ether (NFE) adsorption onto activated carbon fibers and different-sizeactivated carbon particles. J. Coll. Interface Sci. 228:220-225 (2000).

[13] Mallouk, K.E., D.L. Johnsen, and M.J. Rood: Capture and recovery of isobutane by electrothermal swing adsorption with post-desorption post-desorption liquefaction. Environ. Sci. Technol. 44(18):7070-7075 (2010). 
[14] Liu, W., and S. Adanur: Desulfurization properties of activated carbon fibers. J. Eng. Fiber. Fabr. 9(2):70-75 (2014).

[15] Baderin Osman, A.M Leman, N.M Razif Noraini and Norshah Afizi Shuaib. Market Surveillance of Filtering Facepiece (FFP) of Respirator Protective Equipment (RPE): Malaysian Perspectives Materials Science and Engineering. (2020).

[16] Zhuanglei Zou and MaoshengYao. Air flow resistance and bio-filtering performance of carbon Nano tube filters and current facepiece respirators. Journal of Aerosol Science 79 (2015).

[17] Małgorzata Okrasa , Jörn Hitz, Aleksandra Nowak, Agnieszka Brochocka, Christoph Thelen and Zbigniew Walczak. Adsorption Performance of Activated-Carbon-Loaded Nonwoven Filters Used in Filtering Facepiece Respirators. International Journal of Environmental Research and Public Health. (2019)

[18] Khayan Khayan, Taufik Anwar, Slamet Wardoyo and Widyana Lakshmi Puspita. Active Carbon Respiratory Masks as the Adsorbent of Toxic Gases in Ambient Air. Journal of Toxicology. (2019)

[19] Md Sumon Reza, ABM Kamrul Hasan, Shammya Afroze, Muhammad S. Abu Bakar, Juntakan Taweekun, and Abul K. Azad. Analysis on Preparation, Application, and Recycling of Activated Carbon to Aid in COVID-19 Protection. The International Journal of Integrated Engineering. (2020)

[20] Guan, W.J., Zheng, X.Y., Chung, K.F., \& Zhong, N.S. Impact of air pollution on the burden of chronic respiratory diseases in China: time for urgent action. The Lancet, 388(10054), 1939-1951(2016).

[21] Li, D., Zhou, J., Wang, Y., Tian, Y., Wei, L., Zhang, Z., Qiao, Y., \& Li, J., (2019). Effects of activation temperature on densities and volumetric $\mathrm{CO} 2$ adsorption performance of alkali-activated carbons. Fuel, 238(2018).

[22] C. Lorimier, A. Subrenat, L. Le Coq, and P. Le Cloirec, "Adsorption of toluene onto activated carbon fibre cloths and felts: application to indoor air treatment," Environ. Technol., vol. 26, pp. 127-1230, 2005.

[23] Hak-Joon Kim, Bangwoo Han, Chang Gyu Woo, Yong-Jin Kim , Gi-Taek Lim and Weon Gyu Shin. Air Cleaning Performance of a Novel Electrostatic Air Purifier Using an Activated Carbon Fiber Filter for Passenger Cars. IEEE Transactions On Industry Applications. (2017).

[24] Myungjoon Kima, Gi-Taek Lima, Yong-Jin Kima, Bangwoo Hana, Chang Gyu Wooa, and Hak-Joon Kim. A novel electrostatic precipitator-type small air purifier with a carbon fiber ionizer and an activated carbon fiber filter. Journal of Aerosol Science. (2018).

[25] Hyungseok Nama, Shuang Wangb,and Hee-Rok Jeongc. TMA and H2S gas removals using metal loaded on rice husk activated carbon for indoor air purification. Fuel 213 (2018).

[26] Johannes Altmann, Daniel Rehfeld, Kai Tr€ader, Alexander Sperlich, and Martin Jekel. Combination of granular activated carbon adsorption and deep-bed filtration as a single advanced wastewater treatment step for organic micropollutant and phosphorus removal. Water Research 92 (2016).

[27] Shashika Madushi Korotta-Gamage and Arumugam Sathasivan. A review: Potential and challenges of biologically activated carbon to remove natural organic matter in drinking water purification process. Chemosphere 167 (2017).

[28] Y. Wang, B.-Y. Gao, W.-W. Yue, Q.-Y. Yue, Adsorption kinetics of nitrate from aqueous solutions onto modified wheat residue, Colloids Surf. A. Physicochem. Eng. Asp., 308 (2007).

[29] A.A. Babaei, A. Azari, R.R. Kalantary, B. Kakavandi, Enhanced removal of nitrate from water using nZVI@ MWCNTs composite: synthesis, kinetics and mechanism of reduction, Water Sci. Technol., 72 (2015).

[30] A. Azari, A.-A. Babaie, R. Rezaei-Kalantary, A. Esrafili, M. Moazzen, B. Kakavandi, Nitrate removal from aqueous solu $\neg$ tion by carbon nanotubes magnetized with nano zero-valent iron, J. Mazandaran Univ. Med. Sci. (JMUMS), 23 (2014).

[31] M. Ahmadi, A.H. Mahvi, Z. Doroud, B. Ramavandi, P. Teymouri, Kinetic and equilibrium studies of nitrate adsorption from aqueous solution by lewatite FO 36, Environ. Eng. Manage. J., 15 (2016).

[32] Mehdi Ahmadia, Hasan Rahmani, Bahman Ramavandi, and Babak Kakavandi. Removal of nitrate from aqueous solution using activated carbon modified with Fenton reagents. Desalination and Water Treatment. (2017).

[33] Syieluing Wong, Norzita Ngadi, Ibrahim M. Inuwa, and Onn Hassan. Recent advances in applications of activated carbon from biowaste for wastewater treatment: A short review. Journal of Cleaner Production 175 (2018).

[34] Sabrina Sorlini, Michela Biasibetti, Maria Cristina Collivignarelli and Barbara Marianna Crotti. Reducing the chlorine dioxide demand in final disinfection of drinking water treatment plants using activated carbon. Environmental Technology (2015). 